\title{
THE COMPARISON OF ORE RAW MATERIALS FOR BLAST FURNACE PROCESS BASED ON THE QUANTIFICATION OF SELECTED KEY CRITERIA
}

\author{
Petr BESTA ${ }^{1}$, Kamila JANOVSKÁ ${ }^{1}$, Šárka VILAMOVÁ ${ }^{1}$, Tomáš MALČIC ${ }^{1}$, Adam DRASTICH $^{1}$, \\ Tomáš SEZIMA ${ }^{2}$
}

${ }^{1}$ VSB - Technical University of Ostrava, Ostrava, Czech Republic, EU, petr.besta@vsb.cz

${ }^{2}$ T. G. Masaryk Water Research Institute, Department of Water and Waste Management, Ostrava, Czech Republic, EU, tomas.sezima@vuv.cz

https://doi.org/10.37904/metal.2019.979

\begin{abstract}
The production of iron in a blast furnace requires great quantities of feedstock. Some of the basic raw materials are ore constituents, fuel and other basic additives. Ore feedstock can be bought by steelworks from various sites. The key factor is, naturally, the quality of the ore constituent but also the overall cost of purchase. Production facilities are also forced to consider several sources of supply. The problem in assessing the quality of ores is primarily in the broad range of criteria, which are often categorically different. In order to evaluate ore quality, we can make use of specific criteria or technological indicators. The quantity and range of evaluated parameters offer the use of multicriterial decision-making tools. A broad range of methods and procedures can be applied in this. A great advantage is the quantification of different types of criteria into a single determining parameter. In this research, an analysis of raw ore materials was conducted using multicriterial decisionmaking management tools. The aim of this paper is to mutually evaluate the quality of three selected types of raw ore material in terms of a wider range of criteria. The comparison will be based on the quantification of selected criteria used by crude iron producers. The comparison and its results can then be used for decision making in the choice of suitable raw ore material, but also for further study of the complex quality of the raw ore material. The research was realized in the environment of a selected iron producer in the Czech Republic.
\end{abstract}

Keywords: Ore, criterion, quality, order, rating

\section{INTRODUCTION}

The blast furnace process is based on the synthesis of chemical, physical and mechanical processes. The charge for blast furnaces consists of metal bearing materials, slag-forming substances and fuel. Charge materials for the blast furnace process should consist of a balance of properties, low percentage of fine-grained components, narrow grain distribution and sufficient mechanical strength [1].

A highly competitive environment forces metallurgical enterprises to ever more accurately evaluate all the processes and feedstock. Evaluating raw ore and drawing comparisons between them is very complicated, however, given the number of monitored variables that are a factor in the blast furnace process [2].

The current methods for evaluating the quality of ore feedstock can be categorized generally into two types. The first attempts to simulate the conditions of high heat the ore will be exposed to as it dropped through the blast furnace shaft. The second method involves dedicated tests for determining a selected metallurgical quality indicator $[3,4]$.

In evaluating raw ore, it is important to find a multilaterally based system. One option is to synthesize the selected criteria into one evaluable indicator using selected management tools $[5,6,7]$. This allows metallurgical enterprises to more easily evaluate raw ore materials and also optimize management of the purchasing process [8]. 
The aim of this article is to evaluate two selected tools used in multicriterial decision-making for the evaluation of ores. The evaluation is based on quantifying the relevant criteria. Data were analysed as part of long-term research conducted at a metallurgical enterprise in the Czech Republic.

\section{PROBLEM FORMULATION}

Iron ore is one of the most common minerals. Iron ore sites can be found on all continents. As an element, iron is contained in the earth's crust to different degrees. For mining and the use of iron ore components in blast furnaces, only a limited number of sites are useful, however $[9,10,11]$. The main requirement is a sufficient amount of metal contained in the ore. In rich magnetic and hematite ores, the iron content is around 57-65\%. In limonite ores, iron content can drop to $38 \%$, however. Poor limonite and silicate ores can have a minimum ore grade of $35 \%$. Other related properties are also important, key factors being the chemical composition of elements and minerals such as $\mathrm{S}, \mathrm{P}, \mathrm{Cd}, \mathrm{Zn}, \mathrm{Pb}, \mathrm{As}, \mathrm{Na}_{2} \mathrm{O}, \mathrm{K}_{2} \mathrm{O}, \mathrm{Cr}, \mathrm{Ti}, \mathrm{Hg}$ and $\mathrm{V}$. The content of harmful substances such as sulphur, phosphorus or lead can especially influence the overall quality of the ore [6]. An important group of properties are physical properties such as moisture content, lumpiness, granulometric homogeneity, density or bulk properties. Physical properties are important, because they can affect the performance of the blast furnace process itself. The final category of important properties are technical properties, which include parameters such as strength, abrasion resistance, reducibility or thermoplastic properties [1].

Apart from these categories, others relating to the production cost of iron (price, delivery conditions, transport and other associated logistic parameters) are becoming increasingly important $[12,13]$. In today's highly competitive market, the final price of the produced metal is often a critical parameter, and all the relevant tools used in decision-making need to be accurately quantified [13].

Different principles can be applied to evaluate raw ore materials. One option is to evaluate isolated parameters (properties). Another option is to monitor the technological indicators during the blast furnace process, an interesting option being the weighted order method.

The weighted order method is characterized by finding the total value of the individual variants according to the ranking of the evaluated criteria [14]. It is based on the weighted average of partial rankings of variants according to individual criteria. The optimal variant is then the variant with greatest overall weight. First, the weights of the respective criteria are determined. The variant's evaluated weight is then calculated for each criterion, and finally, the total value of the individual variant is determined. For these calculations, we can use equations (1) and (2):

$$
\begin{aligned}
& h_{i}=m+1-p_{i} \\
& H=\sum_{i=1}^{n} v_{i} \cdot h_{i}
\end{aligned}
$$

where:

$$
\begin{aligned}
& h_{i} \text { - the evaluation of individual variants compared to each criterium } \\
& m \text { - the total number of variants } \\
& p_{i} \text { - the rank of the individual variants compared to each criterion } \\
& H \text { - the total value of the variant } \\
& v_{i} \text { - the weight of the criteria }
\end{aligned}
$$

Another method is based on the principles of measuring Euclidean distance. This method is used to find the distance from a fictive variant [14]. The calculation is based on determining the deviation of each criterion from 
the best value. The cumulative sum of these deviations is then the basis for evaluating the variants. For this calculation, we can use equation (3). The best variant has the smallest distance from the ideal variant $(D j)$.

$D_{j}=\sqrt{\sum_{i=1}^{n} v_{i} \times\left(\frac{x_{i}^{*}-x_{i j}}{x_{i}^{*}-x_{i}^{0}}\right)^{2}}$

where:
$x_{i}^{*}$ - the length of action
$x_{i j}$ - the mean width of the elongated bar
$x_{i}{ }^{0}$ - the mean width of the elongated bar

\section{EXPERIMENTAL WORK}

Three ore types from various deposits were assessed in this research. Data for individual criteria were obtained in cooperation with a metallurgical company located in the Czech Republic. Eight key criteria were selected to evaluate the ores. The criteria were selected by the workers from the field of crude iron production technology in a framework of realized brainstorming. These criteria are the most commonly used in an enterprise for assessing ore quality, whether the ore will be used by the enterprise or offered to suppliers. Five criteria are chemical properties, one criterion is a physical property, one is technological, and the final criterion is cost (price). A list of all evaluated criteria is shown in Table 1. The tested ores originated from sites in Australia, Russia and South Africa. Table 1 shows the respective values for all evaluated criteria.

Table 1 Initial values of criteria of the selected ores

\begin{tabular}{|c|l|c|c|c|}
\hline \multicolumn{2}{|c|}{ Criteria } & \multicolumn{2}{c|}{ Ore Feedstock } \\
\cline { 3 - 5 } & & $\begin{array}{c}\text { Australia } \\
\text { Marillana }\end{array}$ & $\begin{array}{c}\text { Russia } \\
\text { Kursk }\end{array}$ & $\begin{array}{c}\text { South Africa } \\
\text { Sishen }\end{array}$ \\
\hline K1 & Content Fe (\%) & 61.5 & 58.1 & 63.1 \\
\hline K2 & Content P (\%) & 0.075 & 0.039 & 0.063 \\
\hline K3 & Content S (\%) & 0.022 & 0.012 & 0.014 \\
\hline K4 & Content SiO $(\%)$ & 5.75 & 5.3 & 4 \\
\hline K6 & Content Al2O3 (\%) & 3.2 & 0.86 & 1.49 \\
\hline K6 & Homogenity of lumpiness (\%) & 45 & 39 & 40 \\
\hline K7 & Reducibility (\%) & 63 & 62 & 64 \\
\hline K8 & Price $(\$ / t)$ & 74 & 64 & 70 \\
\hline
\end{tabular}

When multicriterial tools are used to evaluate several variants (types of ore), the first step is to determine the weights (importance) of the selected criteria. This was conducted in cooperation with the metallurgical enterprise and the participation of an expert team. The pairwise comparison method was used to determine the weights more accurately. The respondents were required to perform a binomial assessment of the pairs of criteria. The results of the comparisons were then converted into respective weights (Table 3 ).

In order to compare the ores, multicriterial decision-making tools using weighted order and distance from the fictive variant were applied. The weighted order method is based on calculating the ore's rank according to individual criteria. The default values shown in Table 1 were converted into rankings according to the specific degree of fulfilment of each criterion. In the case of criterion $\mathrm{K} 1$ (Fe content) the investigated ores descended in the following order: 1. South Africa (63.1\%), 2. Australia (61.5 \%), 3. Russia (58.1\%). The other rankings were calculated for all other criteria in the same manner (Table 2). 
Table 2 Rank of criteria according to their initial values

\begin{tabular}{|c|l|c|c|c|}
\hline \multirow{2}{*}{\multicolumn{2}{|c|}{ Criteria }} & \multicolumn{3}{c|}{ Ore Feedstock } \\
\cline { 3 - 5 } & Australia & Russia & South Africa \\
\hline $\mathrm{K} 1$ & Content $\mathrm{Fe}$ & 2. & 3. & 1. \\
\hline $\mathrm{K} 2$ & Content P & 3. & 1. & 2. \\
\hline $\mathrm{K} 3$ & Content S & 3. & 1. & 2. \\
\hline $\mathrm{K} 4$ & Content $\mathrm{SiO}_{2}$ & 3. & 2. & 1. \\
\hline $\mathrm{K} 5$ & Content $\mathrm{Al}_{2} \mathrm{O}_{3}$ & 3. & 1. & 2. \\
\hline $\mathrm{K} 6$ & Homogeneity of lumpiness & 1. & 3. & 2. \\
\hline $\mathrm{K} 7$ & Reducibility & 2. & 3. & 1. \\
\hline $\mathrm{K} 8$ & Price & 3. & 1. & 2. \\
\hline
\end{tabular}

These calculated rankings are the prerequisite information for using the weighted order method. The method itself is shown in Table 3. Column $v_{i}$ shows the weights of the individual criteria. Colum $p_{i}$ shows the rank of the given criterion for the individual raw ore material, as described in Table 2. The variable $h_{i}$ is the recalculated rank for each variant (raw ore material), whose value is determined from equation (1). Column $V_{i} h_{i}$ shows the partial value of each criterion for a specific variant (raw ore material). The evaluation parameter is then the sum of these values. The ore feedstock with the greatest sum of the partial value then represents the best variant.

Table 3 Comparison of ores using the weighted order method

\begin{tabular}{|c|c|c|c|c|c|c|c|c|c|c|}
\hline \multirow{2}{*}{ Criterium } & \multirow{2}{*}{$\boldsymbol{v}_{i}$} & \multicolumn{3}{|c|}{ Australia } & \multicolumn{3}{|c|}{ Russia } & \multicolumn{3}{|c|}{ South Africa } \\
\hline & & $p_{i 1}$ & $h_{i 1}$ & $V_{i} h_{i 1}$ & $p_{i 2}$ & $h_{i 2}$ & $V_{i} h_{i 2}$ & $p_{i 3}$ & $\boldsymbol{h}_{i 3}$ & $V_{i} h_{i 3}$ \\
\hline K1 & 0.260 & 2. & 2 & 0.520 & 3. & 1 & 0.260 & 1. & 3 & 0.780 \\
\hline $\mathrm{K} 2$ & 0.090 & 3. & 1 & 0.090 & 1. & 3 & 0.270 & 2. & 2 & 0.180 \\
\hline K3 & 0.150 & 3. & 1 & 0.150 & 1. & 3 & 0.450 & 2. & 2 & 0.300 \\
\hline K4 & 0.110 & 3. & 1 & 0.090 & 2. & 2 & 0.220 & 1. & 3 & 0.330 \\
\hline K5 & 0.110 & 3. & 1 & 0.110 & 1. & 3 & 0.330 & 2. & 2 & 0.220 \\
\hline K6 & 0.050 & 1. & 3 & 0.150 & 3. & 1 & 0.050 & 2. & 2 & 0.100 \\
\hline K7 & 0.080 & 2. & 2 & 0.160 & 3. & 1 & 0.080 & 1. & 3 & 0.240 \\
\hline $\mathrm{K} 8$ & 0.150 & 3. & 1 & 0.150 & 1. & 3 & 0.450 & 2. & 2 & 0.300 \\
\hline$\Sigma$ & & & & 1.42 & & & 2.11 & & & 2.45 \\
\hline \multicolumn{4}{|c|}{ The order of variants } & 3. & & & 2. & & & 1. \\
\hline
\end{tabular}

According to this method, the evaluation showed that the ore with the highest score was from South Africa (2.45), followed by the ore from Russia (2.11) and then Australia (1.42). The second calculation used the method of distance from the fictive variant. The solution is shown in Table 4. Equation 3 was used to calculate the key values. The method is based on calculating the Euclidean distance. The sum of these deviations then represents the final distance from the ideal variant, which is given as parameter $D_{j}$ in Table 4.

We can then use this value to evaluate the individual variants (ores). The variant with the lowest value is then considered the best. According to this principle, the method of distance from the ideal variant described the 
best ore as the material obtained from South Africa $(D j=0.3306)$. The values and rank of the other two ores are shown in Table 4.

Table 4 Comparison of ores using the method of distance from a fictive variant

\begin{tabular}{|c|c|c|c|c|c|c|c|}
\hline \multicolumn{2}{|r|}{ Criteria } & \multirow{2}{*}{$\frac{\boldsymbol{v}_{\boldsymbol{i}}}{0.260}$} & \multirow{2}{*}{$\frac{\boldsymbol{x}_{i}^{*}}{63.1}$} & \multirow{2}{*}{$\frac{\boldsymbol{x}_{\boldsymbol{i}}{ }^{\mathbf{0}}}{58.1}$} & \multirow{2}{*}{$\begin{array}{c}\text { Australia } \\
0.0266\end{array}$} & \multirow{2}{*}{$\begin{array}{c}\text { Russia } \\
0.2600\end{array}$} & \multirow{2}{*}{$\begin{array}{c}\text { South Africa } \\
0\end{array}$} \\
\hline K1 & Content Fe (\%) & & & & & & \\
\hline $\mathrm{K} 2$ & Content P (\%) & 0.090 & 0.039 & 0.075 & 0.0900 & 0 & 0.0001 \\
\hline K3 & Content S (\%) & 0.150 & 0.012 & 0.022 & 0.1500 & 0 & 0.0060 \\
\hline K4 & Content $\mathrm{SiO}_{2}(\%)$ & 0.110 & 4 & 5.75 & 0.1100 & 0.0607 & 0 \\
\hline K5 & Content $\mathrm{Al}_{2} \mathrm{O}_{3}(\%)$ & 0.110 & 0.86 & 3.2 & 0.1100 & 0 & 0.0145 \\
\hline K6 & Homogeneity of lumpiness (\%) & 0.050 & 45 & 39 & 0 & 0.0500 & 0.0347 \\
\hline K7 & Reducibility (\%) & 0.080 & 64 & 62 & 0.0200 & 0.0800 & 0 \\
\hline K8 & Price $(\$ / t)$ & 0.150 & 64 & 74 & 0.1500 & 0 & 0.0540 \\
\hline & & & & $\Sigma$ & 0.6566 & 0.4507 & 0.1093 \\
\hline & & & & $D_{j}$ & 0.8103 & 0.6713 & 0.3306 \\
\hline & & & & Rank & 3. & 2. & 1. \\
\hline
\end{tabular}

\section{RESULTS AND DISCUSSION}

Multicriterial decision-making tools were used to compare the quality of ores from South Africa, Russia and Australia. The respective methods were weighted order and distance from the fictive variant. The weighted order method quantifies the determined ranking according to the quality of fulfilment of the criteria. Therefore, only the ranking of the default values was processed, not the original data. The weighted order method does not allow specific differences between individual values to be identified, only the difference in rank. The second applied method was the distance from the fictive variant. This method calculates the specific value of the criteria that deviates from the best variant. The sum of these deviations in relation to the weight of the respective criterion then represents the assessing parameter. The results of both methods are shown in Table 5. The determined ranking in both cases was identical. The same ranking of ores was obtained in the weighted order method mainly because the differences between them were not significant. The determined ranking was thus not substantially distorted by differences in individual positions. In the case of the distance from the fictive variant method, it is also possible to assess the calculated distance $(D j)$. Examining the calculated values in Table 5, it is clear that the ore from South Africa has a categorically higher value. The value of $D_{j}$ in the case of the first ore $(0.3306)$ is twice that of the ore in second place $(0.6713)$. Logically in this method, the tower value represents the better variant, as it is closer to the ideal variant.

Table 5 Comparison of results from both methods

\begin{tabular}{|l|c|c|c|c|}
\hline \multirow{2}{*}{ Ore } & \multicolumn{4}{|c|}{ Methods } \\
\cline { 2 - 5 } & \multicolumn{2}{|c|}{ Weighted order } & \multicolumn{2}{c|}{ Distance from the fictive variant } \\
\cline { 2 - 5 } & Rank & $\sum \mathbf{V}_{\mathbf{i}} \mathbf{h}_{\mathbf{i}}$ & $\mathbf{R a n k}$ & $\mathbf{D}_{\mathbf{j}}$ \\
\hline South Africa & 1. & 2.45 & 1. & 0.3306 \\
\hline Russia & 2. & 2.11 & 2. & 0.6713 \\
\hline Australia & 3. & 1.42 & 3. & 0.8103 \\
\hline
\end{tabular}

In the case of the method of distance from the fictive variant, not only the assessment of the determined ranking can be used but also the specified values for evaluation. The calculated distance can then be easily converted into a percentage, which simplifies interpretation of the final results. 


\section{CONCLUSIONS}

Using the multicriterial decision-making tools to evaluate ores makes it possible to create a broader range of criteria. Based on categorically different criteria, we can compile a descending order of quality of ore raw materials, but it also quantify the differences between them. In this case, the method of distance from the fictive variant is useful and allows us to measure the differences in quality between the individual ores by comparing a set of dimensionless indicators. From a general perspective, it will become increasingly important for metallurgical enterprises to evaluate and measure the quality of all their processes as well as their feedstock. The use of mathematical tools and methods appears to be an interesting alternative that not only offers a foundation for dealing with suppliers but also the potential to continually improve the quality of all processes.

\section{ACKNOWLEDGEMENTS}

\section{The work was supported by the specific university research of the Ministry of Education, Youth and Sports of the Czech Republic No. SP2019/62.}

The article was created thanks to the project No. CZ.02.1.01/0.0/0.0/17_049/0008399 from the EU and $C R$ financial funds provided by the Operational Programme Research, Development and Education, Call 02_17_049 Long-Term Intersectoral Cooperation for ITI, Managing Authority: Czech Republic Ministry of Education, Youth and Sports.

\section{REFERENCES}

[1] BROŽ, L. Hutnictví železa. Praha: SNTL - Nakladatelství technické literatury, 1988. p. 460.

[2] MOORE, J.J. Chemical Metallurgy. Tokyo: Butterworth-Heinemann, 2013. p. 456.

[3] KREJCAR, O., SPICKA, I., FRISCHER, R. Micro operation system for microprocessor applications. Elektronika Ir Elektrotechnika. 2011. no. 8, pp. 83-88.

[4] GEERDES, M., TOXOPEUS, H., COR, V. Modern Blast Furnace Ironmaking. Amsterdam: IOS Press, 2010. p. 164.

[5] DAFT, R.L., MARCIC, D. Understanding Management. Mason: Cengage Learning, 2009. p. 752.

[6] VIGNES, A. Extractive Metallurgy 1: Basic Thermodynamics and Kinetics. New York: John Wiley \& Sohn, 2013. $344 \mathrm{p}$.

[7] SPICKA, I, HEGER, M. Utilization mathematical and physical models derived therefrom real-time models for the optimization of heating processes. Archives of Metallurgy and Materials. 2013. vol. 58, no. 3, pp. 981-985.

[8] MALINDŽÁK, D., STRAKA, M., HELO, M. and TAKALA, J. The methodology for the logistics system simulation model design. Metalurgija, 2010. vol. 49, no. 4, pp. 348-352.

[9] STRAKA, M., TREBUNA, P., ROSOVA, A., MALINDZAKOVA, M., MAKYSOVA, H. Simulation of the process for production of plastics films as a way to increase the competitiveness of the company. Przemysl Chemiczny. 2016. vol. 95, no. 1, pp. 37-41.

[10] TREBUNA, P., STRAKA, M., ROSOVA, A., MALINDZAKOVA, M. Petri nets as a tool for production streamliniing in plastics processing. Przemysl Chemiczny. 2015. vol. 94, no. 9, pp. 1605-1608.

[11] JONSTA, P., VLCKOVA, I., KRISTAK, L., SPICKA, I., JONSTA, Zdenek. Contribution to the thermal properties of selected steels. Metalurgija. 2015. vol. 54, no. 1, pp. 187-190.

[12] SIKOROVÁ, A., LAMPA, M., SAMOLEJOVÁ, A. Analysis of maintenance costs in metallurgical enterprise. In METAL 2016: 25th International Conference on Metallurgy and Materials. Ostrava: TANGER, 2016, pp. 20192025.

[13] SIKOROVÁ, A., SAMOLEJOVÁ, A., KUBICA, S., MASNÝ, R. Analysis of costs of operation and maintenance of hot-water transfer stations. In CLC 2015: Carpathian logistics congress - conference proceedings. Ostrava: TANGER, 2015, pp. 479-484.

[14] FIALA, P. Modely a metody rozhodování. Praha: Oeconomica, 2012. p. 292. 